\title{
AUTOMATED GENERATION OF CNC PROGRAMS FOR MANUFACTURING: A REVIEW
}

\author{
Perkasa, Lugantha ${ }^{1}$ \\ ${ }^{1}$ Mine Mouth CFPP Department, DSSP Power, Sinar Mas, Bayung Lincir; South Sumatera, Indonesia \\ ${ }^{1}$ Mechanical Engineering Department, Sriwijaya University, South Sumatera, Indonesia
}

\begin{abstract}
A configuration system for a product and model requires a parametric design. Where the system is made first, the first thing that needs to be done is the determination of the model. In this journal will discuss the configuration model that is the application of parametric design methods in the MTO environment. CNC program, the result is a variant of a product with good quality so that it can increase the production quantity. High potential short production time costs incurred a little and increase profits. CNC programs are made with various parameters then proceed with a product configuration system that will automatically run in the CNC program.
\end{abstract}

Keywords: CNC, product individualization, product configuration, make-to-order

\section{INTRODUCTION}

Market demand for a product with a special design and many making the company find a way out to complete consumer orders quickly and products with good quality assurance. [1]

The difficulty faced by the company is how to make products that are ordered specifically one by one but do not spend a lot of time and money to increase profits for the company

The initial design is done by drawing using CAD. Then choose the appropriate configuration to proceed in the CNC program. By entering the MTO environmental configuration that is run to produce the right design product. The company uses the program because it has the advantage of being able to make products with complicated designs. [2]

CNC program (Computer Numerical Control) can produce various types of work, such as cutting, drilling, with the right precision and excellent results. this greatly facilitates the work process and shortens time. [3]

The manufacturing steps will be carried out automatically according to the input given in the $\mathrm{CNC}$ program. The designs drawn using CAD will be carried out in their original form with accuracy. so consumers will be satisfied with the results made by the $\mathrm{CNC}$ program[3]

\section{METHODOLOGY}

The writing of this paper aims to explain how the process of working on a product design that has many variations on how the $\mathrm{CNC}$ program can work on the product from the initial stages, namely the design drawings from CAD and then run through geometric transfers to configurations in the CNC program. this can be seen in the picture[3]

The first step is determining the concept of product images, followed by a configuration that will run in the CNC program.

The second stage determines what approach is needed in running the $\mathrm{CNC}$ program. In this case, the parametric configuration method is chosen, which will be included in the MTO environment.

The third stage shows the results that have been made. After the first and second stages, these results are the initial approach that is determined, and the product can represent the demand from consumers, and the results are concluded in conclusions. In making products that are ordered in a complicated form and ordered in large quantities, it is necessary to

*Corresponding author's email: lugantha.perkasa@ gmail.com 
determine in advance the tools to make it.by choosing features that can realize superior product results by influencing product characteristic features and individualizing product characteristics.

The manufacturing process starts with the approach shown inError! Reference source not found.

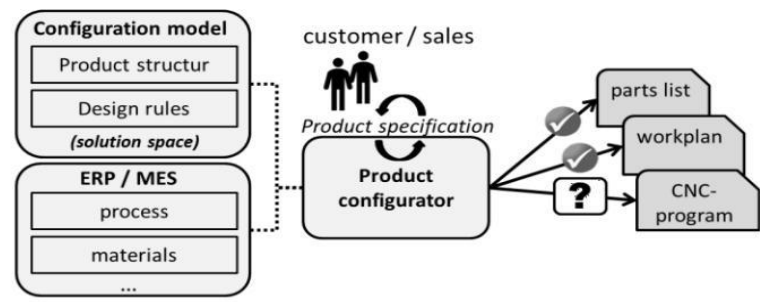

Figure 1 Focus of research CNC

From the picture, it is explained how the effect arising from the approach of single module modulation and modulation approaching individualization in manufacturing to get important opportunities to produce quality products and get customer satisfaction. Various parameters have been explained previously about the approaches that need to be applied by industry in making ordered products in multiple forms and challenging to make.

The first CAD parameter module to be created will be transferred to the general parametric configuration for the geometric requirements to be processed in the $\mathrm{CNC}$ program shown in Figure 2

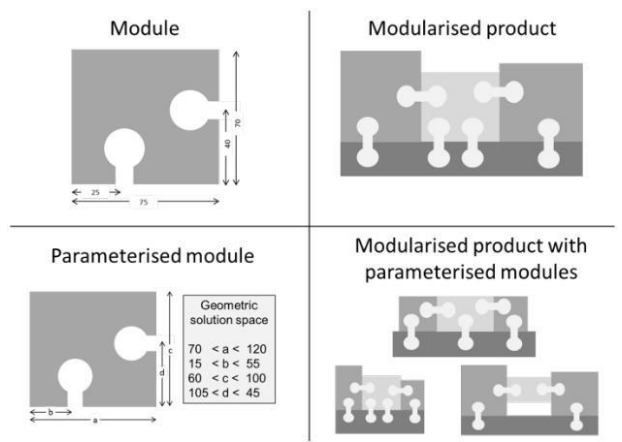

Figure 2 Individualization of products through parameterization

\subsection{Instructions for Making FlatformPump Products with CNC}

Pump system platform construction: starting from the product components that are to be made with a modular system consisting of the main elements (engine, clutch, and pump) and peripheral elements (platform, housing). Then the configuration of all pump components will be made into individual hole patterns up to 40 screw holes in different diameters needed to assemble the pump system on the platform. The following geometry features are individual[4]

Consists of the number of parts that will be made as follows:

1. Position of each hole ( $\mathrm{x}$ and $\mathrm{y}$ coordinates)

2. Diameter and thread of each hole

3. Based unit of valve

The base unit is designed to fit specific applications in the process industry. It is dimensioned according to the process parameters (pressure, temperature, flow rate).

The following geometry features are individualized:

1. Angle of the connecting socket

2. Inner diameters and flange diameter

3. Total length, position

\subsection{Introduction to product configuration and $\mathrm{CNC}$ program generation}

Configuration-based IT products to meet the needs of products ordered by customers with special designs under the request. The features selected in the manufacture determine the result of a product made with that configuration. The first thing to do is arrange the product from the predetermined modules (configuration and selection) and choose the characteristics for this module (parameterization) within the specified configuration limits. These constraints and limitations need to be compiled in the previous configuration model. They ensure that the products are configured, and their characteristics are consistent[4]

The components of software can be adapted in many ways. One of them is the classification for a configurator used in a product. Configuration systems for product identification fulfill the task of product catalogs that, starting from the customer needs, lead to the best-suited product[5].

Product configurators for sales activities focus on simplifying the sales process by guiding the customer through the configuration process. Predefined pictures or CAD models can visualize the product. The result is a complete product specification as well as the specific offer for the configured product variant. 
Production oriented product configurator focuses on the processes once the product has been ordered. Make facilitate order processing and work, preparatory production documents like bills of material, work plans as well as construction plans and drawings are generated automatically [4]

Exclusive products made with a configuration system can include configuration limits and constraints for applying geometric parameters. This parameter can be used to CAD models in components as well as for making $\mathrm{CNC}$ programs

\subsection{Applied Techniques for $\mathrm{CNC}$ Program Generation}

There are two types of configurations that can be applied in CNC programs, namely the CAD system program, and the G-Code.

$C A D / C A M$ programming: One result of the product configuration process can be a CAD model of the individualized part. The CAD model can be used in CAM software (Computeraided manufacturing) to generate the individual $\mathrm{CNC}$ program for the configured part. This configured CAD model, as well as a model of the raw material, is loaded into the CAM software. A technologist generates the tool paths for each feature of the part. The tool paths are saved in a CLDATA (cutter location data) file. Finally, under the use of machine-specific postprocessor software, the tool paths are converted to a CNC program for the assigned machine tool. The resulting CNC program is usually simulated to detect and avoid collisions before the machining process. Automate the CAD/CAM process, the design features of the CAD model are transferred into manufacturing features. Within the CAM software, the tool paths for the manufacturing features can be generated automatically and then be moved by a postprocessor into a machinespecific CNC program. The automation of these steps is possible but extensive. It is limited due to restrictions in automatic feature recognition as well as individual restrictions of the applied software. An approach for CAD/CAM automation in close connection with a product configurator is presented in

G-code Program on CNC Machines. G-code is a function used in the Numerical Control programming language that contains information on the position of a tool to do a job in the factory. G-code is separate from M-code and T-code, which controls the machine and factory equipment.

When G-Code-programing is utilized, each movement of the tool is coded using commands that are listed in DIN 66025/ISO 6983 as well as machine control specific commands[3]

Shop-floor programming facilitates this coding via predefined G-Code sets for standard features. Multiple parametric machining cycles are selected and combined to a CNC program, in which dimensions, as well as technical parameters, are entered

\section{RESULTS AND DISCUSSIONS}

While the CAD / CAM process is based on the product model, the program generator, as well as the parametric programming approach, is based on a predetermined toolpath and works without a product design model. Therefore, the three approaches underlie various restrictions and offer various opportunities to automate the creation of $\mathrm{CNC}$ programs. Continued feature features that process the selection for individual use cases, decision trees can be used to determine how an approach can be taken in parametric programming in machine control or $\mathrm{CNC}$ program generators suitable for the automatic manufacture of each $\mathrm{CNC}$ program. It consists of four necessary inspection steps. It show Figure 3

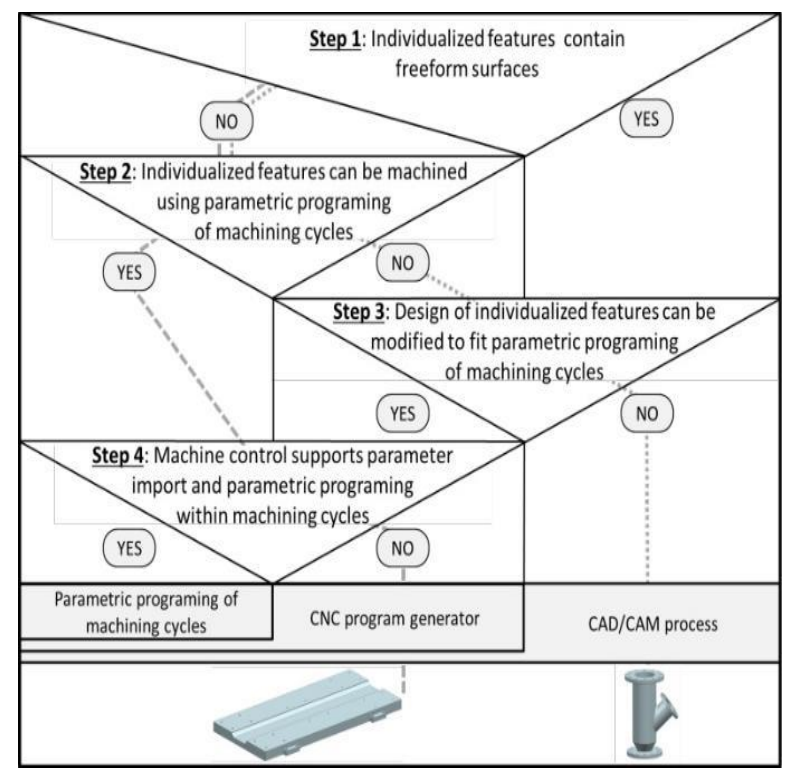

Figure 3Decision tree for program decision approach

The initial stage is determined by drawing up individual geometrical features, including the surface of the free form. If the free-form surface has to be modified, the CNC program can hardly 
be realized by parametric programming of the machining cycle or generated by a CNC code generator. In this case, the CAD / CAM process is mandatory.

The second stage using individual features can be done using the machining cycle parametric program. With the results that can use the application parameters, but requires consideration of the function of the machine tool and control.details that should not be skipped are the making of a chamfer and deburring. If individual features influence the chamfer, the parametric programming of the resulting geometry can be sophisticated. Such attention is also needed when deburring operations, if carried out by machine tools. Shows in Figure 4, an exemplary pocket that is ground into a cylindrical workpiece. While the pocket itself can be programmed with a basic machining cycle (a), the chisel path to grind the chamfer can hardly be programmed using the machining cycle (b).
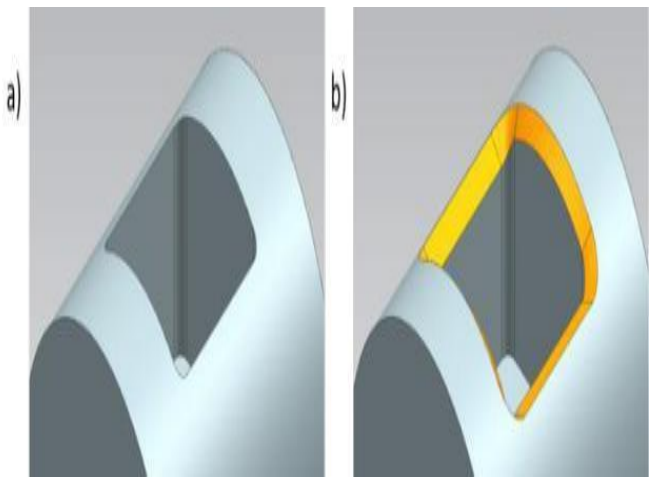

Figure 4 a) pocket without chamfer (b) pocket with chamfer

Figure 4. (a) pocket without chamfer (b) pocket with chamfer

Each step serves to identify the parts that will be created by features ranging from free shapes to complex shapes to be done using the parametric programming of the machining cycle. The next step is identifying the parts of the product design that need to be.

Features must facilitate parametric programming of the machining cycle in effect if individual elements can be worked out using machining cycle parametric programming. They were determined, if the required parameters can be imported from the network to the machine tool control and if the settings can be used in the programmed machining cycle. The universal approach is to import text files that are formatted as CNC programs. In these programs, the application variables are defined by individual values of geometric parameters. The machining program itself is stored in machine control and starts as a subprogram. This subprogram refers to the variable, which is defined in the imported file. If importing parameters into machine tool control is not possible or if imported parameters cannot be used in the machining cycle, a CNC program generator can be applied.

All platform features can be worked out using machining cycle parametric programs. Depending on the machine control used, if geometric parameters can be transferred to the parametric CNC program on the machine tool or if a CNC program generator is needed.

Making the pump casing starts from the results of the image, which will then be read into the program to be done. the pump to be made will be translated into a platform where the number of holes will be made equal to the number of available platforms that can be seen in Figure 5 shows the exemplary pump system

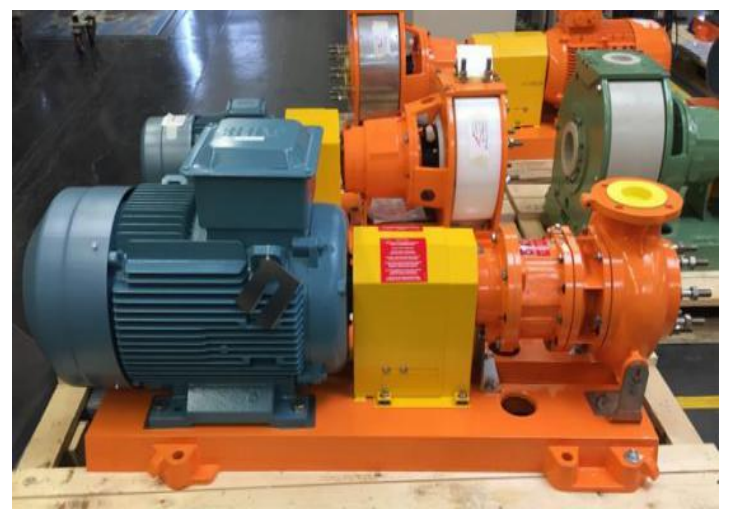

Figure 5 Platform based pump system

During the product configuration process, one XML file is created. The resulting form of ERP will be continued to the software then automatically selects the XML file from the order released in the ERP system and forwards it to the CNC program generator. After that, the parameters in the CNC generator program and handed back to the software assistant. If there is an error, there will be a warning again that will enter the program. The results will be entered into the CNC program control in a particular folder. Operators can immediately start the generated CNC program. When the platform's "machining" step is confirmed in the ERP system, the software assistant removes the CNC program from the network folder. The basic 
functions of the CNC program generator are shown inFigure 6

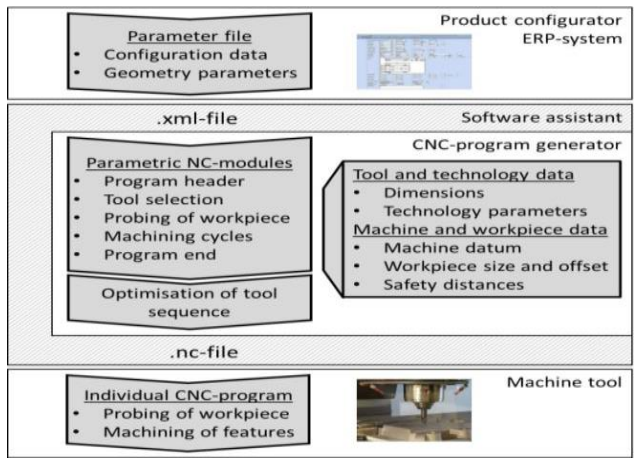

Figure $6 \mathrm{CNC}$ program generator for the exemplary use case

In addition to the information contained in the XML parameter file, the CNC program generator requires general information about the process. This is a tool and technology data, as well as machine data. This information is listed in the table in the program generator and can be easily modified. The core of the generator are parametric CNC modules for the "probing" and "machining" steps. For the machining process, one $\mathrm{CNC}$ module is programmed for each feature (boring, counterbore grinding, and screw milling). This $\mathrm{CNC}$ module contains the G Code with control information for the machine tool. Instead of fixed values for tool numbers, positions $\mathrm{x}, \mathrm{y}$ and $\mathrm{z}$, movement, spindle speed, and feed rate, this module is based on variables. According to the features required, $\mathrm{CNC}$ modules are selected and combined. Next, the workpiece datum is set, and the variables for the position and size of the feature are replaced by the values

\section{CONCLUSION}

Writing this paper aims to make the reader understand how the CNC program works to produce products that are customer orders to companies where the product must be made accurately according to customer desires. And this paper explains from the initial design stage to the manufacturing process the method used is the use of MTO configurations into the configuration environment. There are many examples disclosed here, such as pump components that are made automatically in the CNC program. In this case, there are Limitations of the two approaches resulting from the geometry of parts and control of machine tools discussed. While CAD / CAM processes are suitable for complex geometries, the possibilities for automating CAD / CAM processes are limited.

Conversely, the direct transfer of parameters into a CNC program can be fully automated, while it is limited to geometry that can be worked out using parametric machining cycles. It determines the procedure that is most suitable for a particular application case, and a decision tree is introduced. Exemplary implementations are presented, which proves the potential of making automated $\mathrm{CNC}$ programs in industry practice.

Further research must be carried out to reduce the limitations of making automated CNC programs. Therefore an approach to combine CAD / CAM produced by the CNC program part with the parameterized CNC program part can be developed, and geometric design limitations for automated CNC programming must be specified. This limit can be applied as a limitation of the product design process to enable the creation of automated CNC programs for individual products.

\section{REFERENCES}

[1] Y. Koren, "The Global Manufacturing Revolution," Glob. Manuf. Revolut., 2010, doi: 10.1002/9780470618813.

[2] G. Schuh, S. Rudolf, and M. Riesener, "Similarity-Based Product Configuration," Procedia CIRP, vol. 17, pp. 290-295, 2014, doi: 10.1016/j.procir.2014.01.056.

[3] C. Schaede, S. Seifermann, and J. Metternich, "Automated Generation of CNC Programs for Manufacturing of Individualized Products," Procedia CIRP, vol. 72, pp. 1251-1257, 2018, doi: 10.1016/j.procir.2018.03.064.

[4] D. Zukunft and A. Industrie, "Umsetzungsempfehlungen $F\{\ddot{u}\} r \quad$ Das Zukunftsprojekt Industrie 4.0," no. April, 2012.

[5] S. Kinkel and S. Maloca, "Econstor," no. January, 2010. 